\title{
QUANTIFICATION OF PESTICIDE RESIDUES IN SOME SOILS OF NARSHINGDI AREA
}

\author{
M. Amin Uddin ${ }^{1}$, M. Alamgir Z. Chowdhury, Z. Fardous and M. Hasanuzzaman \\ Agrochemical and Environmental Research Division, Institute of Food and Radiation Biology \\ (IFRB), Atomic Energy Research Establishment (AERE), \\ GPO Box-3787, Dhaka-1000, Bangladesh
}

Results of residual pesticides in soils of Narshingdi district showed that out of 9 samples, only two contained organochlorines, namely DDT and DDE ranging from 0 - 0.726 and $0.404-0.563$ $\mu \mathrm{g} / \mathrm{kg}$, respectively. While, organophosphorous, carbamate and pyrethroid residues were found below the detection limit. However, the contamination level of DDT and its metabolites was lower as compared to the IAEA/FAO/Codex Alimentarious Guide line value.

Usage of pesticides in Bangladesh is relatively low (300 g active ingredient/hectare) as compared to other countries of the world and even much lower than India (380 $\mathrm{g}$ a.i/hectare). However, consumption of pesticides has increased in recent years with the introduction of high yielding varieties of crop to control pest and diseases (Kuhr and Dorough 1977, Nath and Chakraborty 1978, Chowdhury et al. 2002a). About 25,479 tons formulated products were used in 2005 compared with 15,906 tons in 2001 and 18,090 tons in 2003 (Rahman 2007). Chemical fertilizers and pesticides have contributed significantly to improve yields of crops, increasing the production of food grains from 9.7 million $\mathrm{mt}$ in 1961 to about 20 million mt in 1993 (Matin 1995). Use of pesticides has to be controlled to avoid contamination of food supplies and ecological imbalance, but present measures in Bangladesh are inadequate and farmers rarely implement standards (Matin et al. 1998).

Indiscriminate use of pesticides apart from being occupationally hazardous in the environment poses a serious threat to human health too. International development research centre, Ottawa, has claimed that every year about 10,000 people die and 4, 00,000 people suffer from various effects of pesticide poisoning in developing countries (Gupta 1989). Literature suggests that information regarding the significance of persistence of pesticide residues in soil is scanty in Bangladesh. So, an attempt was undertaken to assess the types of pesticide residues (i.e. organochlorine, organophosphorous, carbamate and pyrethroid) used and their concentration levels in some selected soils extensively used for vegetables and rice cultivation in Narshingdi district.

Soil samples collected from nine selected spots of high land vegetables and low land paddy fields of Narshingdi district were immediately kept in refrigerator in glass containers in the laboratory. The samples were dried at room temperature in a fume cupboard and grounded to fine powder. Fifty g soil sample was extracted with $100 \mathrm{ml}$ mixed solution of hexane and acetone (1 : 1) by using electronic shaker. The extract was treated with $5 \mathrm{~g}$ anhydrous sodium sulphate to remove

\footnotetext{
${ }^{1}$ Author for correspondence: <aminifrb@yahoo.com>.
} 
traces of water. The extract was subjected to clean-up using florisil column chromatography (DFG Manual of Pesticide Residue Analysis 1987). The top $1.5 \mathrm{~cm}$ of the florisil column was packed with anhydrous sodium sulphate. Elution was done with $2 \%$ diethyl ether in hexane $(5 \mathrm{ml} / \mathrm{min})$. The eluate was concentrated in a rotary vacuum evaporator and transferred to glass-stoppered test tubes. Solvents were completely removed under mild nitrogen flow. The evaporated sample was dissolved in hexane and made to volume $(1 \mathrm{ml})$ in a volumetric flask for subsequent gas chromatography.

Determination of pesticide was done by Gas Chromatography (Hewlett Packard 5890 II) and High Performance Liquid Chromatography (Detector-waters 486, Pump-Waters 515) by injecting a portion of aliquot. Identification of the pesticide was carried out in relation to the retention time of the pure analytical standard supplied by International Atomic Energy Agency (IAEA), Austria. Quantification was made with a freshly prepared standard curve of the standard pesticide. GCECD (ECD- Electron Capture Detector) mode was used for the detection of Organochlorine pesticide residues, and HPLC was used for the detection of organophosphorus, carbamate and pyrethroid pesticide residues.

Out of nine soil samples, only two were found to contain organochlorines, namely DDT and its metabolites DDE (Table 1). A typical chromatogram of the sample and the corresponding standard were shown in Figs 1a, b. Residues of organophosphorous, carbamate and pyrethroid were found below detection limit. However, the contamination level of DDT and its metabolites was very low ranging from 0 to $0.726 \mu \mathrm{gDT} / \mathrm{kg}$ and 0.404 to $0.563 \mu \mathrm{g}$ DDE $/ \mathrm{kg}$ as compared to the IAEA/FAO/Codex Alimentarious Guide line value. Rahman et al. (2006) showed that out of ten soil samples of Kushtia region, only one soil contained organochlorines, namely DDT and its metabolite DDE. Most of the organochlorines (OCs), including DDT, lindane, aldrin, dieldrin, are no longer registered in the country. However, DDT and other organochlorine compounds were used in the country until recent past (Alam et al. 1999). In the 1980s, substantial quantities of OCs were used in agriculture (Matin et al. 1998). The persistent nature of OCs and their translocations remain as residues in agricultural land (Alam et al. 1999). Degradation of pesticides in soil is influenced by environmental conditions. The way the pesticides are formulated also affects their dissipation resulting finally in residue consisting of the original compound and/or its metabolites (Sattar 1991). Better understanding about degradation of pesticides in soil and the factors affecting the process may help in its judicious application to reduce environmental pollution (Chowdhury et al. 2002b).

Although, the Pesticide Rule (PR) 1985 of Bangladesh strictly prohibits any kind of unauthorized use of pesticides but because of lack of strong monitoring and proper evaluation facilities, this regulation did not work effectively to control hazardous pesticides. Proper regulatory enforcement of the relevant rules and provisions, and regular monitoring of residues would prevent misuses and could minimize the environmental problems. 
Table 1. Organochlorine pesticide residues in soil.

\begin{tabular}{|c|c|c|c|c|c|}
\hline \multirow{2}{*}{$\begin{array}{c}\text { Sample } \\
\text { code }\end{array}$} & \multirow{2}{*}{$\begin{array}{l}\text { Sample } \\
\text { location }\end{array}$} & \multicolumn{4}{|c|}{ Pesticides $(\mu \mathrm{g} / \mathrm{kg})$} \\
\hline & & DDE & DDD & DDT & Total DDT \\
\hline S-1 & Shibpur, Narshingdi, Paddy Field & 0.563 & ND & 0.726 & 1.29 \\
\hline $\mathrm{S}-2$ & " & ND & ND & ND & - \\
\hline S-3 & $"$ & ND & ND & ND & - \\
\hline S-4 & $"$ & ND & ND & ND & - \\
\hline S-5 & Shibpur, Narshingdi, Vegetable Field & ND & ND & ND & - \\
\hline S-6 & " & ND & ND & ND & - \\
\hline S-7 & $"$ & ND & ND & ND & - \\
\hline S-8 & $"$ & 0.404 & ND & Trace & 0.404 \\
\hline S-9 & $"$ & ND & ND & ND & - \\
\hline
\end{tabular}

Detection limit for GC: $0.1 \mu \mathrm{g} / \mathrm{kg}$, ND: Not detected.

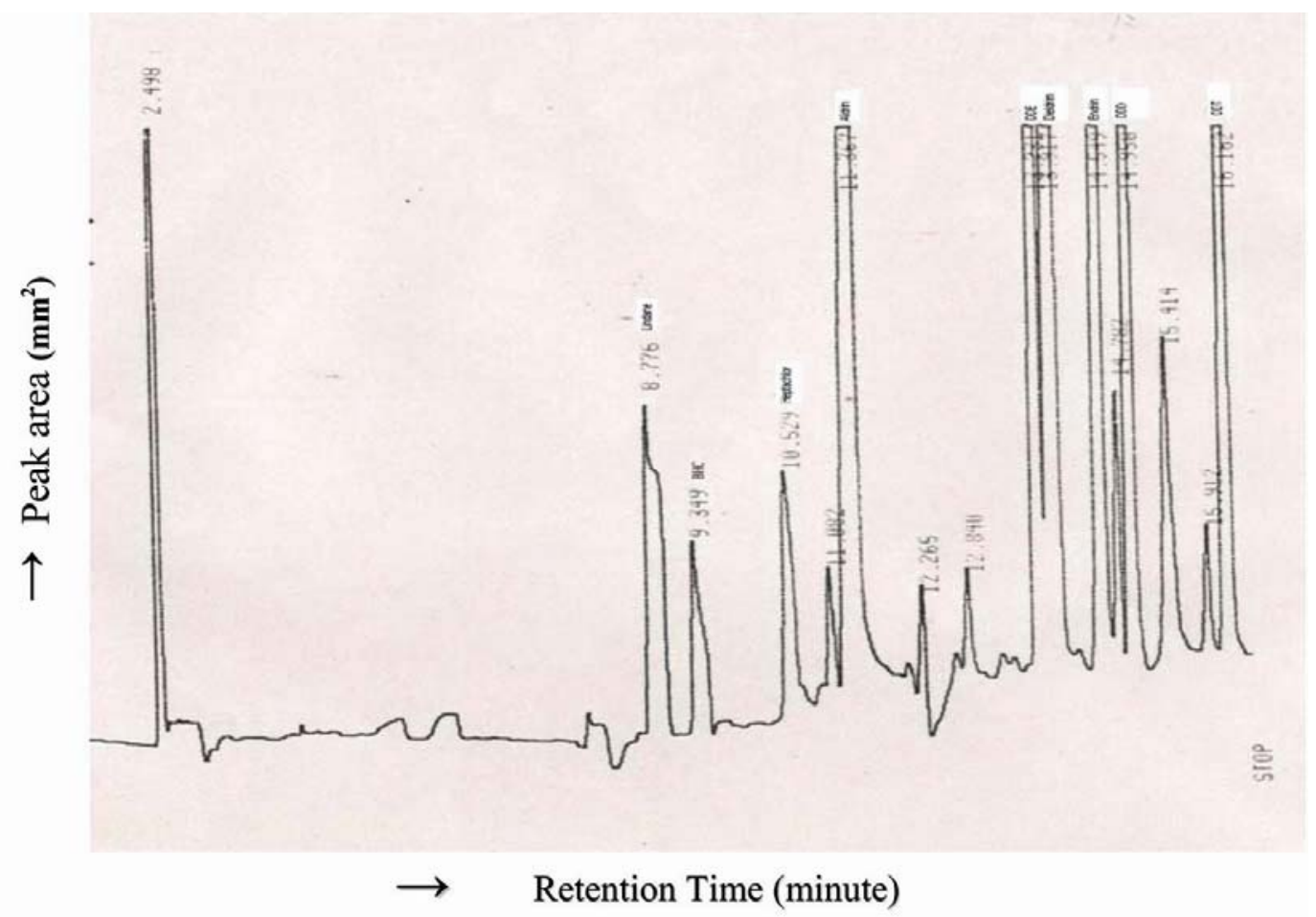

Fig. 1a. A typical chromatogram of mixed standard of lindane, BHC, Heptachlor, Aldrin, DDE, Dieldrin, Endrin, DDD and DDT. 


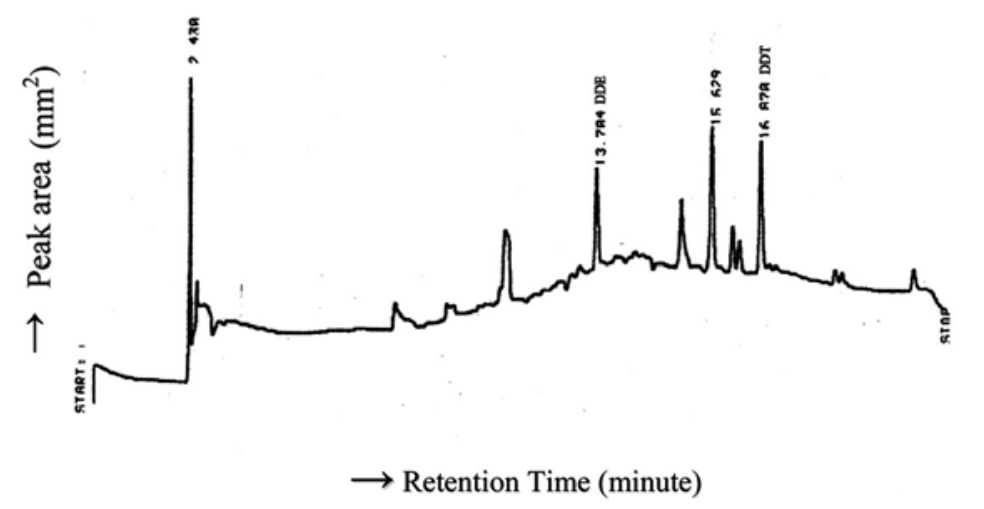

Fig. 1.b. Chromatogram of the soil sample contaminated with DDE and DDT residues.

\section{References}

Alam, M.M., N.G. Das, M.M. Rahman and M.A. Malek. 1999. Organochlorine insecticide residues in water and soil of the Meghna Dhonagoda irrigation project of Bangladesh. J. Asiat. Soc. Bangladesh, Sci. 25(1): 135-142.

Chowdhury, N., S.M. Ullah, M.A. Malek and M.M. Rahman. 2002a. [14C]-carbofuran degradation in four different soils of Bangladesh. Dhaka Univ. J. Biol. Sci. 11(1): 67-73.

Chowdhury, N., M.A. Malek, S.M. Ullah and M.M. Rahman. 2002b. Fate of [14C]-carbofuran pesticide studied in a sandy loam soil in laboratory conditions. J. Asiat. Soc. Bangladesh, Sci. 28(1): 19-26.

DFG Manual of Pesticide Residue Analysis. 1987. Pesticide Commission, Weinheim, New York, NY: VCH. 1: 297-307.

Gupta Y.P. 1989. Pesticide poisoning. Sci. Rep. 26(9): 491-492

Kuhr, R.J. and H.W. Dorough. 1977. Carbamate Insecticides, Chemistry, Biochemistry and Toxicology. CRC Press, Boca Raton, Fl. p. 178.

Matin, M. A. 1995. Environmental pollution and its control in Bangladesh. TRAC Trends in Analytical Chemistry 14: 468-473.

Matin, M.A., M.A. Malek, M.R. Amin, M.S. Rahman, J. Khatoon, M. Rahman, M. Aminuddin and A.J. Mian. 1998. Organochlorine insecticide residues in surface and underground water from different regions of Bangladesh. Agriculture, Ecosystems and Environment 69: 11-15.

Nath, D.K. and B.B. Chakraborty. 1978. Control of brinjal (Solanum melongena) fruit and shoot borer, Leucinodes orbonalis Gueen. (Pyralidae: Lepidoptera) by soil application of granular insecticides. Pesticides 12(10): 27-28.

Rahman Mahbubar. 2007. Pesticides and Environmental Pollution: Mitigation approach and measures, 2007. T.M.: Support of the facilitating the development and spread of the IPM collaborative research support program, BARC, Dhaka, pp. 4-12.

Rahman, M.M., M.S. Rahman, M. Amin Uddin, M.A Z. Chowdhury and M. Hasanuzzaman. 2006. Pesticide residues in soils of some selected spots of Bangladesh. J. Asiat. Soc. Bangladesh, Sci. 32(2): 243- 248.

Sattar, M.A. 1991. Degradation of the residues of aldrin, dieldrin and endrin in two Bangladesh soils. $J$. Asiat. Soc. Bangladesh, Sci. 17 (2): 145-153. 